\title{
INNOVATION IN CONDUCTING WRITING RETREATS FOR ACADEMIC STAFF IN HIGHER EDUCATION
}

\section{B. Dube}

School of Human and Social Sciences

University of Venda

Thohoyandou, South Africa

e-mail: Bevelyn.Dube@univen.ac.za

\section{S. B. Maphosa}

Africa Institute of South Africa (AISA)

Human Sciences Research Council

Pretoria, South Africa

(Adjunct Professor, School of Human and Social Sciences, University of Venda, Thohoyandou, South Africa).

e-mail: smaphosa@hsrc.ac.za

\section{Mershon}

Department of Politics

University of Virginia

Charlottesville, VA, USA

e-mail: mershon@virginia.edu

\section{K. Miner-Romanoff}

Academic Affairs

Franklin University

Columbus, Ohio, USA

e-mail: karen.miner-romanoff@franklin.edu

\section{ABSTRACT}

How do researchers and administrators in higher education plan and carry out writing retreats for academic staff? This paper presents a distinctive approach to developing creative writing retreats for academic staff in higher education. We distill lessons from our June 2016 writing retreat, which drew participants from the University of Venda and the University of Limpopo. Responding to the South African Journal of Higher Education's invitation to 're-imagine' writing retreats, we specify the shortcomings of linear writing retreats and discuss how to enhance collaboration, participation, and leadership capacity in planning and carrying out writing retreats. We also focus on an oftneglected yet crucial feature of retreats, follow-up. As we show, our approach offers general insights for creative designing and implementing writing retreats. 
Keywords. Research productivity, collaboration, gender equity, follow-up/follow through, community of practice, self-efficacy

\section{INTRODUCTION}

How do researchers and administrators in higher education plan and carry out writing retreats for academic staff? This paper presents a distinctive approach to designing and implementing participatory writing retreats for academic staff in higher education. Our approach distills lessons from the June 2016 writing retreat we led, a retreat drawing participants from the University of Venda (UNIVEN) and the University of Limpopo (UL), in South Africa. UNIVEN and UL are rural universities that were originally established under the apartheid regime's policy of separate, ethnically based institutions of higher learning. They are both located in Limpopo Province of South Africa. UNIVEN is situated in Thohoyandou Vhembe district. It was established in 1982 under the then Republic of Venda government to serve the inhabitants of Venda bantustan. After 1994, the new democratic South African government reform of tertiary education rehabilitated UNIVEN to a comprehensive university offering both theoretically oriented and practically oriented courses. UL is sited in Turfloop farm in Sovenga town and was established in 2005 by the merger of the University of the North and the Medical University of South Africa (MEDUNSA). These previous institutions form the Turfloop campus (in Limpopo) and MEDUNSA campus (in Gauteng) of the university.

The remarkable recent growth in research outputs at UNIVEN and UL, has depended on resource mobilization, research capacity development, advanced research strategy, provision of infrastructure and strengthening capacity to support young academic staff and postgraduate students. Both universities have made significant progress by setting up research and innovation departments and encouraging productivity in addressing the challenges that confront them and in meeting the strategic objectives and associated targets to strengthen their core business of academic projects. These include teaching and learning, research and community engagement.

Further, both universities' corporate strategies respond to the three-part call of the country's Department of Higher Education and Training (DHET), National Research Foundation and National Development Plan (NDP) to: (i) enhance research and innovation through increased numbers of National Research Foundation (NRF) - rated researchers and increased research outputs aligned to DHET targets; (ii) ensure quality teaching and learning through a higher education system able to improve continuously as members of the higher education community collaborate to share best practices and solve shared problems; and (iii) promote greater investment and greater gender equity in research and development.

As a result, UNIVEN and UL over the last decade have continued to post significant growth in peer-reviewed research outputs as measured by the Department of Higher Education 
and Training (DHET) in terms of its policy for the annual accreditation of scholarly publications. ${ }^{1}$ For instance, at UNIVEN, research outputs per unit increased from 58.3 in 2009 to 198 in 2013; publication units per capita increased from 0.19 in 2009 to 0.44 in 2013; and, the number of National Research Foundation (NRF) rated researchers increased from 2 in 2009 to 15 in 2013 (University of Venda Annual Report 2014). Moreover, the research outputs of accredited publications at UL increased from 107.01 in 2006 to 147.55 in 2011 (University of Limpopo Annual Research Report 2012).

Nonetheless, these achievements are not reaching the desired impact of research productivity and transformation. In particular, a projection of larger Center for Higher Education Transformation (CHET) cross-national higher education performance indicators reveal a low ranking location of the two universities in the wider context of contemporary universities. A 2010 CHET report identified three different university clusters in South Africa based on knowledge productivity (function) indicators, namely: Red, Blue and Green clusters (Boshoff 2010). The Red cluster constitutes the top research-intensive universities. The Blue cluster consists of institutions focused primarily on technical training, while the Green cluster includes institutions which show characteristics of both missions. UL and UNIVEN are associated with negative growth (and appear in the blue and green bands, respectively) as far as ISI paper output is concerned especially in social sciences and humanities (Boshoff 2010). Based on this analysis, writing retreats are a fundamental pillar of infrastructure provision and hold promise for strengthening capacity and improving research performance and productivity.

\section{THE CALL}

The South African Journal of Higher Education's (SAJHE's) invitation to 're-imagine' writing retreats calls attention to a pressing need to enhance the effectiveness and relevance of writing retreats for academic staff in contemporary higher education. Responding to that call, we address six central concerns. The way that we meet each concern corresponds in turn to the unique context that drives our approach.

Our first concern is the need to enable and leverage collaboration in academe. Accordingly, the first distinction of our approach is that we emphasize collaboration both among the retreat's leaders the retreat's participants. Collaboration is multi-term, starting before the retreat and continuing both during the retreat and after it. Moreover, collaboration is multitier, for not only does it unfold within the departments or schools sending participants to a retreat, but also it strengthens intellectual exchange and collaboration across a given university and among universities, at both national and international levels. 
Second, we highlight that, whereas the participants' preparatory work prior to the retreat is essential, standardization in stage of writing is not required. On the contrary, papers at different stages of the production process are encouraged. At minimum, participants must bring to the writing retreat their titles, abstracts, and outlines. Full drafts are also most welcome. Preparation for the retreat involves not only work on writing but also the mentors' encouragement of positive collegial relationships between the mentors and the participants well before the actual writing retreat.

Third, building collegial relationships should be linked to building leadership capacity, which means identifying a cohort of participants who will commit themselves to the retreat and also inviting participants to choose a leader among themselves whom they trust to facilitate communication between mentors and participants before the retreat. The participant-leader could, for instance, coordinate preparatory work in advance of the retreat and encourage participants to draft their titles, abstracts and drafts, which would then be sent to the mentors prior to the workshop. Combining the first three concerns, participants not only learn to collaborate as they prepare for the workshop but also, at the workshop, learn from each other and teach each other given variation in stages of writing. As a result, the responsive nature of our approach is the integration of leadership capacity and active, ongoing participation.

Fourth, participants who share elements of a common intellectual background yet also differ from each other in cultural, geographical, professional, or other characteristics make for a compelling writing retreat. For example, attendees could be drawn from multiple departments and disciplines, yet share the experience of working in the same school. The mixture of diverse intellectual perspectives yet familiarity with the same workplace and colleagues is likely to foster vibrant intellectual exchange.

Fifth, the retreat should offer support for new writers and junior scholars in both the collective forum and one-on-one interactions. To help participants navigate the publication process, the participant-leader, in collaboration with the mentors, can motivate the participants to overcome insecurities and foster trust and confidence among participants. The mentors can with the entire group discuss basic principles of targeting journals and responding to reviseand-resubmit judgments, and in one-on-one meetings tailor advice on such matters to each participant's paper. Throughout all stages and sessions of the retreat, the mentors, the participant-leader, and the participants themselves create a supportive environment for writing and revision. Last, we underscore an often overlooked aspect on writing retreats, follow-up, which can take different forms. As we show, follow-up can be an iterative process that amounts to 'follow through'. 
The remainder of the paper proceeds as follows. The next section discusses the origins and evolution of writing retreats. It is followed by how to plan for creative writing retreats, and how to implement them. The last section is devoted to follow-up, and, the conclusion considers the broader implications of our approach.

\section{WRITING RETREATS}

Writing retreats originated in North American universities in the late eighteenth century (Aitchison and Lee 2006). The popularity of writing groups and retreats spread in the US and elsewhere through the student-centred learning and process writing movements of the 1960s and 1970s, respectively (Gere 1987). Aitchison and Lee (2006) emphasize that recent research writing retreats across different institutions and countries draw on quite distinct strands of theoretical work on writing and learning. In Australia, for instance, they observe there has been a diversity of emerging approaches and practices. Furthermore, Aitchison (2003) appropriated an explicitly language-oriented perspective in her work with research writing groups. In contrast, George at al. (2003) described multidisciplinary peer-initiated research writing retreats. Groups of different kinds formed by Grant and Knowles (2000) and Lee and Boud (2003) drew on a range of theoretical perspectives including feminist and post-structuralist framings. In Scotland and Ireland, Murray and MacKay (1988) and Moore (2003), respectively, drew extensively from North American composition studies.

Although there is no single approach to writing retreats, writing retreats have in common the purpose of providing an ambience of peace and quiet - away from 'normal business' of teaching - that fosters creativity, learning, and inspiration and, thus, aids academic staff and graduate students in reaching their writing goals. The writing retreat offers an opportunity for guidance, networking, fellowship, and focus, in a period of seclusion without isolation or deprivation.

Writing retreats, then, have a vital role to play in higher education. In South Africa, racism and patriarchy were key features of colonialism and apartheid and, thus, also powerfully shaped higher education. The result was a racialization and gendering of a predominantly white and male academic work force and concentrated in urban universities. Today, there is an urgent need to produce a new generation of academics that not only includes black and women South Africans but also colleagues in rural universities. This new generation must in addition possess the intellectual and academic capabilities related to teaching and learning, research and community engagement that provide a necessary condition for transforming and developing South Africa's universities. In recent years, pressures on academics have greatly increased, as 
academic work has come to embrace new and more diverse forms of activity; research and writing have come to the fore as central promotion criteria. Accordingly, creative writing retreats offer a critical path for this antidote. In order to provide support for these new scholars, adoption and adaptation to context-specific situations in terms of 'strategic learning' and 'knowledge management' targeted towards addressing a perceived inequity and 'performance gap’ within the current higher education policy and practice environment (George et al. 2003), may lead to greater and more diverse scholastic success.

Importantly, today 'academics must learn to integrate fragmenting roles ... and navigate the increasingly contested terrain of higher education' (MacLeod, Steckley and Murray 2012, 652). Research and writing remain as indispensable elements of the mission and work of universities (e.g., Lukhele-Olorunju, Maphosa and Mutanga 2014). Thus, academic staff need also to engender a cultural habit of the mind to perceive writing as a task not 'separate from, and subordinate to, their primary activities of knowledge creation via research and knowledge exchange via teaching' (Aitchison and Lee 2006; Street 1984). As Lee and Boud (2003) emphasize, this shift has profound implications for individual staff members and for entire institutions of higher learning as all struggle to redefine the nature of their work and to adopt new practices in an environment of ongoing evolution and change. The challenges of balancing teaching, research, and writing are especially great in universities serving under-served community contexts including rural universities. Thus, writing retreats for academic staff need to be developed for a variety of contexts, including new disciplines, professional fields not traditionally part of core university sectors, under-resourced universities, and rural universities.

As we discuss below, active engagement, re-imagined leadership and follow-up in the inspired retreat are central to enhancing participants' confidence in their own capacity to progress in the writing process. The retreat explicitly recognizes that writing for publication can be daunting and that many talented scholars do not see their projects through to completion. Hence the innovative retreat tackles barriers to writing head-on so as to build participants' selfefficacy as successful writers. The innovative retreat fosters a community of writers who learn to pursue strategies for writing amid competing demands (e.g., Murray 2012).

The distinctions of the retreat proposed here include: collaboration; preparation in multiple forms; active participation, collegiality, and leadership capacity; the 'border crossing' that so often advances the frontier of knowledge (cf. Mershon and Walsh 2016); support; and followup that amounts to 'follow through'. As a natural next step, we discuss how to plan imaginative retreats. 


\section{PLANNING FOR INNOVATIVE WRITING RETREATS}

The success of a writing retreat depends on how well the retreat is planned. According to White (2015), the most important aspect of planning of a writing retreat is defining and disseminating its goals. Everyone intending to participate in the writing retreat should understand those goals and support them. Otherwise, the retreat could descend into chaos with participants pursuing different or conflicting goals (White 2015). As Benvenuti, Castle and Keane (2013) argue, it is the responsibility of a mentor to predetermine the aims and outcomes of the writing retreat and to ensure that these support academics in their efforts to flourish as researchers.

The June 2016 writing retreat (like the first writing workshop conducted in $2015^{2}$ is an initiative of the research office in the SHSS at UNIVEN and funded by the university's Research and Innovation Department. In its second year, the retreat is set to continue for the foreseeable future as an indispensable space encouraging research writing productivity. The retreat was led by three mentors, external experts in the category of professors and chief research specialist, all with extensive international field research, teaching and writing experience. Accordingly, this mentor-process was itself 'innovative' as part of the team brought western experience (from the University of Virginia and Franklin University) and another part brought African experience (from the Human Sciences Research Council of South Africa). The coordination team comprising mentors, the head of the research office in the SHSS, the dean of the SHSS and participant-leader who is a lecturer in the SHSS, held several discussions via email, telephone and skype before the retreat. Because the retreat is an initiative and undertaking of UNIVEN, it was the research office in the SHSS at UNIVEN that engaged and made arrangements for collaboration with the Humanities and Social Sciences (HSS) division of UL. In accordance with UNIVEN's strategic plan, the SHSS identified the overarching aim of the June 2016 writing retreat as boosting the research output of female academics in the school and by extension increasing the school's research output. A total of 28 members enlisted for the retreat, as follows: 24 academic staff, 3 graduate students, and one non-academic employee. Again, all participants were females.

The coordination team was well aware that a gender imbalance exists generally with regards to women's global participation and promotion in systems of innovation, including universities and research and development $(\mathrm{R} \& \mathrm{D})$ productivity. The need to address this imbalance is especially pressing in Africa. Moreover, African rural universities in particular continue to lag behind in gender equality in education, writing, and productivity overall. For instance, a breakdown of academic staff by gender from 2009 to 2014 (excluding non-South 
Africans) at UNIVEN revealed that out of total a 302 in 2009 only 96 were females, with 206 males; and, out of a total of 372 in 2014, only 129 were females, with 243 males (CHET South African Higher Education Open Data 2014 update, 2016). As for imbalance at UL, out of a total of 746 in 2009, only 307 were females, with 439 males; and, out of a total 941 in 2014 only 406 were females, with 535 males (CHET South African Higher Education Open Data 2014 update, 2016). Hence the writing retreat itself and its deliberate focus on participation on the part of female academic staff and graduate female students marked a milestone in its multifaceted effort to address gender-based inequities in R\&D productivity, empower females, and enhance the prospects of female career progression.

Further, the coordination team was mindful not only of the parameters set by UNIVEN and its SHSS but also of the challenges faced by academic staff in contemporary universities. The team recognized that, although publication rates give an important metric of academic and university success, rates among most faculty members remain low (Salager-Meyer 2014). Moreover, the stress and strain of coping with the peer review process and manuscript rejection may lead some faculty to abandon their publishing efforts (Horn 2015). Indeed, De Rond and Miller (2005) claim that only the elite have the resources, time, and platform upon which to publish. Yet the failure to disseminate via publication diverse types of research that might enhance understanding and advance knowledge can have profoundly negative effects for the academic and broader communities. A greater number of academics need to publish their research so that it might inform practice and understanding outside the academy, generate broader societal benefits, and build their own professional acumen (Salager-Meyer 2014). The June 2016 coordination team also recognized that linear writing retreats are simply not effective as a means of reaching the goal of greater publication.

The coordination team, thus, strove to devise plans and practices all directed at attaining the SHSS overarching aim and all fitting within the UNIVEN strategic plan. We worked to ensure that the retreat would not only enhance the participants' research writing skills, but that it would also give them an opportunity to work on their current papers, which they would then submit to specific journals for publication.

The coordination team asked the participants to play an active role in setting their own goals for the writing retreat. Whilst acknowledging that the mentor, as an expert, is a critical element in the setting up of goals of a writing retreat, we were convinced that allowing the participants to state their needs in the planning stage would not only help us determine the genuine concerns of the participants, but would also give them an opportunity to take control and 'ownership' of the process. We recognized that the enrolled participants had different 
competency levels in writing papers meant for publication. Accordingly, it was important for us not to recognize that these women's needs were not homogenous. We saw our task as designing a writing retreat that would respond to the women's needs as spelt out by the women themselves, as they felt - and experienced - ownership of the retreat. Of course, at the same time, we of the coordination team engaged their needs carefully within the broad auspices of the research office that served as the organizing authority for the retreat. In this way, we equipped ourselves to achieve goals defined in tandem by the participants themselves, by the team, and by the SHSS at UNIVEN as the responsible authority commissioning the writing workshop.

As another key part of our planning, we deliberately consulted the participants on what they wanted in the retreat programme. This exercise was vital because, through it, participants were able to express what they expected of the three-day retreat. We made use of the participantleader, a female academic chosen by enlisted participants themselves, to serve as a bridge between the participants, mentors and the research office of the SHSS as organizers. The participant coordinator invited the prospective participants to a meeting where all involved could discuss the retreat programme. After extensive consultation with the prospective participants, it became clear to the participant-leader that the participants wanted to focus primarily on writing their articles with the help of mentors so that, by the end of the retreat, they would have their manuscripts in a polished and near-final form, ready or almost ready to be considered for publication. They made it clear from their inputs that they did not want the kind of writing retreat where they are talked to, but that they wanted a 'hands-on' practical retreat. The proposed programme was passed on to the mentors, who, with a few minor adjustments, approved it. Thus, to set up the goals of the retreat, we took into consideration what participants wanted to achieve. With that, the retreat was ready to begin.

Participants were also given an opportunity to choose the off-campus site that they perceived as most welcoming to and encouraging of writing. Also on this aspect, the retreat participants took an active part in the planning process; and collaboration, inclusion, and engagement started even before the retreat itself. In multiple ways, unlike in customary retreats where participants walk in with no pre-retreat participation, ours were actively involved in determining the venue and direction that their retreat would follow.

With participants' expectations captured in the writing retreat programme, we realized that it was imperative that we as mentors gain insight into the kinds of research we would encounter at the retreat. After all, the SHSS at UNIVEN has eight departments, covering diverse fields of study, and colleagues within any one department have distinct specializations. We, 
therefore, requested that participants send us the titles and abstracts of their manuscripts so that we might learn of the participants' work and stage of development before the retreat convened. The participant-leader asked the women academics to send their abstracts to her, and these were compiled into a list and then sent to the coordination team three weeks before the actual retreat.

We also requested that draft papers, even incomplete ones, be sent to us a week before the retreat so that we could work on them and have comments ready by the time the retreat started. Thus, the process of mentoring the participants as writers started well before the retreat itself. In addition, through the exchange of titles, abstracts, and draft papers, follow-up loops and linkages were established. The coordination team, moreover, could use our observations of the papers received from participants in order to prepare our support so that it was tailored to suit the specific needs of a particular participant. This arrangement also gave the mentors adequate time to have a one-on-one meeting with the participants early on in the writing retreat.

In sum, the June 2016 retreat suggests that inclusive, intensive, extensive, and multi-stage planning paves the way for creative writing retreat. We now address what such retreats look like on the ground.

\section{INNOVATIVE WRITING RETREATS IN PRACTICE}

The re-imagined writing retreat moves beyond the practice of lecturing attendees on aspects of writing and publication, and instead engages the participants in a collaborative process in which the participants actively work on improving their writing and enhancing their abilities to publish. It creates and sustains a community of practice at the retreat and beyond and provides peer-to-peer and mentor support to its participants in the short and long term. Further, it is open to diverse disciplinary and interdisciplinary approaches at the same time that takes into account and addresses the peer review process as an objective necessity of rigor and publication. The re-imagined writing retreat has multiple goals and thoughtfully designed structures to measure and meet those goals. These assertions were evidenced by the organic collegiality that mushroomed from the initiation and planning stages and laid a foundation for building a community of practice. In effect, the consultation and inclusion of participants, mentors and organizers in the design of the retreat was itself drawing from and extending the experience of the previous retreat of 2015 .

The June 2016 coordination team sought to build collegiality from the very start of the writing retreat and even before the retreat. The aspect of building collegiality was important to lay pillars of trust, cohesion and coherence of emerging community of practice. In opening the retreat, we welcomed the participants warmly and invited each participant to introduce herself 
to all others. In this way, each and all contributed to the retreat's collective identity as a community of writers. The re-imagined retreat embraced a hands-on approach in which participants actually participated, took responsibility for their work, engaged in small-group discussions, and met one-on-one with their mentors about the finer points of revising their research and manuscripts. As noted, in advance of the face-to-face retreat, the mentors and participants began to exchange drafts of their work in order to accelerate progress in person and offer an immersive environment of familiarity and support upon arrival. With the iterated collegial exchanges, before and well beyond the retreat, the workshop had greater impact as evidenced by the survey conducted at the end of the retreat wherein participants expressed such opinions as:

If it can continue for five years, women will grow.

The workshop was very helpful to me a student researcher. Many other students will benefit if they were to be included.

The exchanges also provided the mentors with the ability to arrive at the retreat prepared to discuss aspects of research, writing, journal selection, and publication based upon those participants' needs.

The coordination team offered retreat participants the opportunity to work on papers at various stages of completion, affording each participant targeted advice, skill development, and guidance as she revised and advanced her work toward completion. The mentors drew on their extensive and diverse experiences to discuss both the mechanics of writing for publication and ways to overcome, thoughtfully and directly, the less obvious hurdles to writing and publishing. Knowledge sharing was flexible rather than linear, with some issues revisited as they arose during the mentoring sessions throughout the retreat. Another form of flexibility appeared in the multiple uses made of any given hour: as some participants met one-on-one with mentors, others devoted time to revising their drafts. By the time the retreat came to a close, therefore, it had assured each participant time alone with a mentor as well as time to revise her draft. Informal discussions with colleagues in small groups and over tea and meals also provided invaluable follow-up feedback as the participants and mentors fully focused on writing as an immersive experience.

Equally important to emphasize, the re-imagined retreat enabled participants to conceive of and practice writing as an iterative process. Participants came to see through their own experience that writing entails revision and that revision entails multiple iterations, with each revision honing and strengthening the writing. The organization of the retreat drove home the 
conception and practice of writing as an iterative process, for it featured multiple sessions in which participants revised and refined their papers during the retreat itself. As themes arose, the leaders addressed them so as to reinforce best practices. This iterative nature of the reimagined retreat equipped the writers to move their manuscripts forward and take immediate responsibility for their own writing and goal achievement.

Group-wide discussions during the June 2016 retreat covered a range of issues vital to writing for publication. The discussions, while group-wide, were customized to the participants' contextual and professional experiences and expectations. The topics included paper organization and essential elements, methodological requirements, plagiarism, quotations, and referencing, journal selection, the rigors and challenges of peer-reviewed journals, and disseminating work to the academic community and broader societal communities. Even the full-retreat sessions, however, included the opportunity for dialogue and robust discussion, which increased critical engagement and further empowered participants. Aided by the group-wide sessions, the participants could reflect on the recommendations they had received, revise, and seek immediate and further guidance and mentoring. This iterative process allowed the writers to edit, reflect, and refine within an intense and relatively short period of time. With these features, our re-imagined retreat as designed and implemented in June 2016 led many participants to report feeling empowered to continue working after the official retreat ended, indicating an improvement in motivation and self-efficacy. Figure 1 illustrates the features of the June 2016 writing retreat just discussed.

Figure 1 represents the iterative and participatory flow of the retreat and the development of a community of practice. It is our hope that the June 2016 retreat holds insights for other institutions of higher education. The design and implementation of this re-imagined writing retreat can be customized for diverse contexts, for other individuals and groups who also seek collaborative learning and skill building, motivation to write and publish, within a cohesive environment.

\section{SEALING THE SUCCESS OF INNOVATIVE WRITING RETREATS: FOLLOW-UP AND FOLLOW THROUGH}

Any follow-up to a writing retreat is usually treated as occurring only after a retreat has ended. Yet in our view and based on the experience of the June 2016 writing retreat, follow-up should be a cooperative process, developing gradually, sustained throughout a writing retreat, and continuing afterwards. As we saw and continue to live the relationship, a writing retreat's follow-up ideally serves as ‘follow through’ to maintain writing and publishing. 


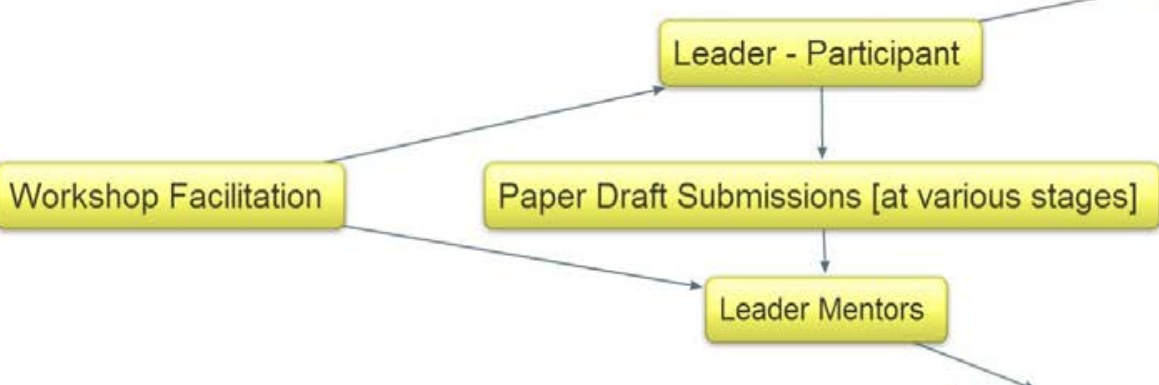

Iterative Paper Comments and Analysis

Needs Assessment- Ongoing

Peer-to-peer Community of Practice and Support

Sense of Cohesion- Idea Exchange
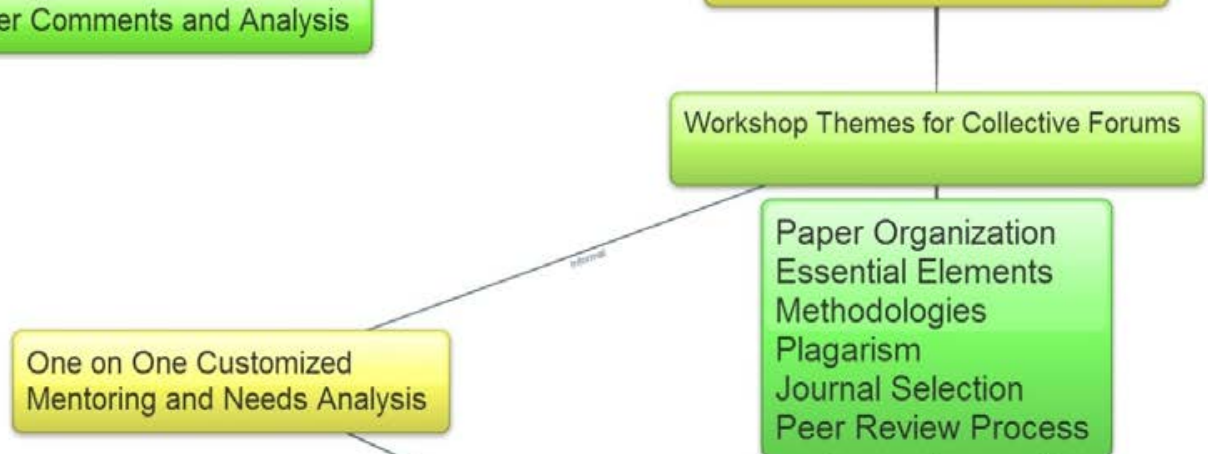

Awarness of Others

Increased Capabilities

Motivation \& Self Efficiency

Sharing- Small Groups

Cumulative Knowledge Building

Results in:

High Completion

Psychological Preparadness

Publication

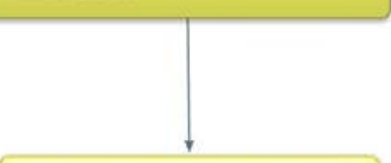

Contributions to Society

Figure 1: Innovation in designing and conducting writing retreats for academic staff in higher education

(The figure illustrates the features of the June 2016 writing retreat discussed in this article.) 
How can follow-up to writing retreats work to increase writing and research productivity among academic staff in higher education? Reviews of theories and models of research and writing in higher education have abounded in recent decades, and have treated the nature, dynamics, and assessment of writing retreats along with the influence of the retreats' various follow-up features on productivity (e.g., Boice 1997; Galligan et al. 2003; Gere 1987; Lee and Boud 2003; Moore 2003; Murray and MacKay 1998; Natriello 1987). In accordance with Boud and Lee (2005), our retreat follow-up addressed the epistemological, experiential, and textual dimensions of the participants' research and writing productivity. This was especially appropriate for rural universities. Follow-up enabled learning through receiving and responding to feedback, even at the retreat itself; and, addressed questions of knowledge, textual practice, and identity also underscored by Aitchison and Lee (2006). Ideally, our feedback formed part of follow-up focused on direction and motivation for research and writing productivity more than on certification and selection assessment. ${ }^{3}$ Shepard (2000) claims that follow-up increasingly demands moving away from 'assessment of writing' to 'assessment for writing', so as to support writing productivity and underpin rather than undermine confidence, achievement, and progress. Our follow-up, thus, held the potential to boost research and writing capacity at the individual, institutional, and national levels. For instance, the retreat survey elicited such replies as

This was a wonderful workshop because people worked closely with the mentors and actually wrote manuscripts. This was different from the traditional writing workshops which are talk shows.

Workshops like this are helpful to beginners like me. I wish these were conducted twice a year.

The coordination team conceived of and carried out follow-up as a crucial, iterative, and gradual process throughout the writing retreat. Follow-up did not suddenly materialize, as is often misconstrued, once the writing retreat concluded. True, the coordination team asked the retreat's participants to fill out a survey just before the end of the retreat, as a way of discerning what aspects of the retreat the participants perceived as working well and what on the other hand might have been improved. Reflections on the survey stand as just one part of follow-up, however. Thus, long-term application and knowledge sharing pervaded all stages. Follow-up continues today, well after the retreat. The workshop has metamorphosed into a group committed to co-authoring a special issue of a professional journal. 
These achievements reflect in turn the frequent consultation between and among the research office and dean of SHSS, mentors, participants, and the hosts at the retreat site. The dialogue among these individuals and groups enabled a mutually satisfying process of programme development, deployment of resources, preparation and choice of retreat site, definition and refinement of the agenda, recruitment of and discussion with participants, and exchange of titles and abstracts of working manuscripts. This iterative process did much to build trust and foster a sense of membership within the new writers' community. This process enabled the participant-writers to become adept at dealing with mentors' feedback, seeking constructive criticism, and offering constructive criticism to peers as they moved towards completing and submitting manuscripts. The fledgling multidisciplinary community of peerinitiated research writing and its accomplishments - once again, the writing group has already completed and submitted a special issue proposal - demonstrates the success of the creative dynamic enabled by the June 2016 retreat.

In our experience, a writing retreat capable of producing these results displays four related characteristics. Specifically, first, the writing retreat was open to participants' diverse conceptions of knowledge production and diverse specializations. Second, the retreat's participants were linked in different ways to the retreat's external environment, for example, department, school and university affiliation. Third, the retreat both embraced diversity (though all females, participants differed in academic levels, subject specializations, extent of manuscript writing, staff positions and age) as a source of rich intellectual exchange and also tailored guidance and feedback to all participants’ specific concerns. Last, the retreat offered each participant the opportunity and support for growth and development of their abilities.

Follow-up as an iterative process, not as a 'one-shot deal' occurring solely at the very end of a retreat, becomes a set of ongoing relationships enabling increased capabilities, motivation, and self-efficacy. Follow-up as follow through included cumulative knowledge building within small groups meeting during and after retreat sessions. The relationships from this June 2016 retreat were explicitly negotiated, self-determining, self-directed, dynamic, and inherently responsive to the agendas and articulated needs of each individual and the group (cf. Aitchison and Lee 2006; Grant and Knowles 2000; Moore 2003). The clusters of participants in small groups benefited from vital intellectual exchange, while one-on-one consultation with mentors also provided invaluable pedagogical feedback in the retreat. This 'horizontalizing' pedagogy of small-group discussion, chunking the learning, and work empowered participants as peers, and strengthened their work with the mentors, who served as more experienced researchers and writing specialists. This set of practices embodied the dual notion of both being - and becoming 
- a peer participant, able to aid and advise other peers, moving beyond a participant-expert 'vertical' dyadic relationship and creating a more dispersed, 'horizontal', and community-based pedagogy emphasized by Aitchison and Lee (2006) and Boud and Lee (2005).

Thus, the re-imagined writing retreat was distinctive in that its insights were not imparted from mentor-as-expert to participant but rather mutually shared, as mentors led participants and participants engaged in peer-to-peer development of insights. Thus, our retreat fostered peerto-peer learning and support, generated completion of manuscripts, psychological preparedness, and also determination to publish, as indicated by such survey comments as:

Collaborating with people in other institutions.

To have hands on article writing sessions on individual basis to ensure that comments are effected immediately and ... for review.

As the June 2016 retreat's participants collaborate in the ongoing community of practice, they demonstrate that they are empowered as writers, committed to the substance of their writing, and convinced of its value.

\section{CONCLUSION}

Writing retreats have a measurable impact on facilitating what is often a daunting task of writing in higher education. The challenges of writing are especially pronounced for academic staff in rural universities. This article, while acknowledging the diverse ways to 'do' writing retreats, offered a multi-stage, inclusive, participatory, consultative, and collaborative design for retreats, one that enhances leadership capacity and self-efficacy, that promotes gender equity, and that furnishes mentoring from experts while also fostering peer-to-peer mentoring. Innovative retreats such as that we conducted can equip participants to take responsibility for their writing, moving their manuscripts forward, and achieving their goals. With these features, the re-imagined retreat can empower participants to continue working after the official close of a retreat, as motivation and self-efficacy are improved. As we have shown, follow up, allowed the coordination team and the participants to follow through with each other before the retreat, during the retreat, and afterwards. The re-imagined retreat, then, is highly likely to yield a community of practice committed to and engaged in writing well beyond the retreat itself.

\section{ACKNOWLEDGEMENTS}

Mershon acknowledges research support in the Arts, Humanities, and Social Sciences, University of Virginia. 


\section{NOTES}

1. In 2003, the then Department of Education (DoE) published its Policy and Procedures for the Measurement of Research Output of Public Higher Education Institutions. This policy was applied from the 2004 output onwards. Outputs in a given year are always measured a year later, e.g., the 2011 outputs assessed in 2012.

2. The first Writing Retreat for Academic Publication (WRAP) at UNIVEN organized by the research office in the school of humanities and social sciences (SHSS) took place 12-15 October 2015 at Tzaneen Country Lodge, Limpopo. The workshop was facilitated by Dr. Sylvester B. Maphosa, one of the 2016 facilitators. It was attended by 33 participants (15 females and 18 males); all from the SHSS at UNIVEN. The workshop aimed to show participants how to present research to a journal editor and a scientific audience with an eye to publication. All participants brought manuscripts at different stages of development, which at the retreat were subjected to a rigorous group peer review including one-on-one guidance from the mentor facilitator. At the time of the second WRAP workshop in June 2016, seven articles from the cohort of 2the015 retreat had been published in peer-reviewed journals.

3. Natriello's 1987 review categorised the full range of assessment purposes as certification, selection, direction, and motivation.

\section{REFERENCES}

Aitchison, C. 2003. Thesis writing circles. Hong Kong Journal of Applied Linguistics 8(2): 97-115.

Aitchison, C. and A. Lee. 2006. Research writing: Problems and pedagogies. Teaching in Higher Education 1(3): 265-278.

Benvenuti, S., J. Castle and M. Keane. 2013. The nature and purpose of writing retreats in a shifting higher education landscape. Heltasa 2013: Higher Education Learning and Teaching Association of Southern Africa. http://www.unisa.ac.za/contents/conferences/Heltasa2013/docs/Full\%20 paper\%20111.Benvenuti\%20et\%20al.pdf

Boice, R. 1997. Strategies for enhancing scholarly productivity. In Writing and publishing for academic authors, ed. J. M. Moxley and T. W. Taylor, 19-34. Lanham, Maryland: Rowman and Littlefield.

Boshoff, Nelius. 2010. Cross-national higher education performance indicators: ISI publication output figures for 16 selected African universities. Paper prepared for the Higher Education Research and Advocacy Network in Africa (HERANA). Centre for Higher Education Transformation (CHET), Cape Town. www.chet.org.za

Boud, D. and A. Lee. 2005. 'Peer learning' as pedagogic discourse for research education Studies in Higher Education 30 (5): 501-516.

De Rond, M. and A. N. Miller. 2005. Publish or perish: Bane or boon of academic life? Journal of Management Inquiry 14(4): 321-329.

Galligan, L., P. Cretchley, L. George, K. Martin-McDonald, J. McDonald and J. Rankin. 2003. Evolution and emerging trends of university writing groups. Queensland Journal of Educational Research 19(1): 28-41.

George, L., K. Martin-McDonald, L. Galligan, P. Cretchley, J. McDonald and J. Rankin. 2003. Issues that confront professional women entering academe through non-traditional academic career paths. Paper presented at the Researching Research Agendas Conference, Perth, Western Australia, 2003.

Gere, A. R. 1987. Writing groups: History, theory, and implications. Carbondale, IL: Southern Illinois University Press.

Grant, B. and S. Knowles. 2000. Flights of imagination: Academic women be (com) ing writers. International Journal for Academic Development 5(1): 6-19. 
Horn, S. A. 2015.The social and psychological costs of peer review stress and coping with manuscript rejection. Journal of Management Inquiry: 11-26.

Lee, A. and D. Boud. 2003. Writing groups, change and academic identity: Research development as local practice. Studies in Higher Education 28(2): 187-200.

Lukhele-Olorunju, P., S. B. Maphosa and S. S. Mutanga. 2014. Science, technology, innovation and human security in Africa: Issues, challenges and lessons. Africa Insight 44(2): 158-180.

MacLeod, I., L. Steckley and R. Murray. 2012.Time is not enough: Promoting strategic engagement with writing for publication. Studies in Higher Education 37(6): 641-654.

Mershon, C. and D. Walsh. 2016. Diversity in political science: Why it matters and how to get it. Politics, Groups, and Identities: 1-5.

Moore, S. 2003. Writers' retreats for academics: Exploring and increasing the motivation to write. Journal of Further and Higher Education 27(3): 333-342.

Murray, R. 2012. Developing a community of research practice. British Educational Research Journal 38(5): 783-800.

Murray, R. and G. MacKay. 1998. Supporting academic development in public output: Reflections and propositions. The International Journal for Academic Development 3(1): 54-63.

Natriello, G. 1987. The impact of evaluation processes on students. Educational Psychologist 22(2): 155-175.

Salager-Meyer, F. 2014. Writing and publishing in peripheral scholarly journals: How to enhance the global influence of multilingual scholars? Journal of English for Academic Purposes 13: 78-82.

Shepard, L. A. 2000. The role of assessment in a learning culture. Educational Researcher 29(7): 4-14.

Street, B. 1984. Literacy in theory and practice. Cambridge: Cambridge University Press.

University of Limpopo Annual Research Report. 2012. Division of Research Development and Administration. Marketing and Communication University of Limpopo, Turfloop Print Press: 5.

University of Venda Annual Report 2014 - Creating Future Leaders. 2014. p. 89. www.univen.ac.za

White, A. 2015. How to plan a writing retreat. Part 1: Goals and Rules. Alex White: Writer, last modified: 18 March 2015. http://www.alexrwhite.com/how-to-plan-a-writing-retreat-part-1goals-and-rules/ 